\title{
Research and Exploration on the National Traditional Sports Resources in Lancang River Valley under Culture Oriented Background
}

\author{
Lujun Li \\ Oxbridge College,Kunming University of Science and Technology, \\ Kunming Yunnan 650106
}

\begin{abstract}
In this paper, we conduct research on the national traditional sports resources in Lancang river valley under culture oriented background. Really in Chinese traditional sports culture must be confirmed and reflect on the moment, only a clear definition of the concept of national traditional sports and category, figuring out what is the Chinese nationality traditional sports activity, which is a folk activity, and modern competitive sports, we can suit the remedy to the case, targeted, heritage and development path of the respective work, realize the diversification of the Chinese nation traditional culture heritage and development. Specifically the Lancang river valley region sports should be payed special attention for the preservation of the tradition.
\end{abstract}

Keywords- Lancang River, Traditional Sports, Culture Oriented, Exploration, Basic Resources.

\section{Introduction}

National traditional sports is a national characteristics of preserve one's health, general fitness and entertainment activities. National traditional sports as an important part of national culture that is the essence of the Chinese nation outstanding traditional culture, national traditional sports culture is the product of all the national long-term historical development as is the national political, economic and cultural life of a special report, with the typical national features, show the core characteristic of the relative independence. Traditional Chinese sports culture pays great attention to spiritual and inner harmony, harmony with idea of harmony of the charm in today's highly developed science and general technology to show the unique meaning and value [1-3].

According to the literature review, the functionality of the national traditional sports could be listed as the follows. (1) The spiritual value of national traditional sports culture. National sport is not only a competitive entertainment activities, it is endowed with the value of primary national unity, national self-confidence and the national spirit, to enhance the sports participants in the national consciousness and patriotism, sense of responsibility, inspired the sense of national pride for the sports fans. (2) The ethical and moral education of national traditional sports culture value. Ethical and moral concepts in daily life is shown as a kind of behavior standards that can put each nationality's traditional cultural values through the way of people's moral behavior, become people to abide by the rules, for the long time in the process of the national development plays enlightenment and the edification. (3) National traditional sports culture of fitness and entertainment value. With constant improvement of standard of living of people of all ethnic groups in China, has a great interest of traditional ethnic sports will become the important content in the life of the national culture, it will bring more joy to the people of all ethnic groups in the spare time life and happiness [4].

The relative popularity of cultural education as make the public has the knowledge structure and ability to enjoy the mass culture. In the history of the development of high culture and mass culture is concerned, the former is much long history than the latter. Reason is that during the 
formation of high culture and education far from popular, it's just very few people enjoy privileges. Today, education has the certain popularity. Chinese culture is the basic hypothesis of human goodness, think people can be implemented by means of introspection of the good in human nature when a person realizes the good in human nature, to reach one's own internal harmony, and the people own inner harmony is the foundation of all harmony. Beyond the basic hypothesis of human goodness is shown as moderation, humility, tolerance, automatic control, such as values, these are to achieve this kind of means that is also a person of virtue which could be reflected from the following figure.

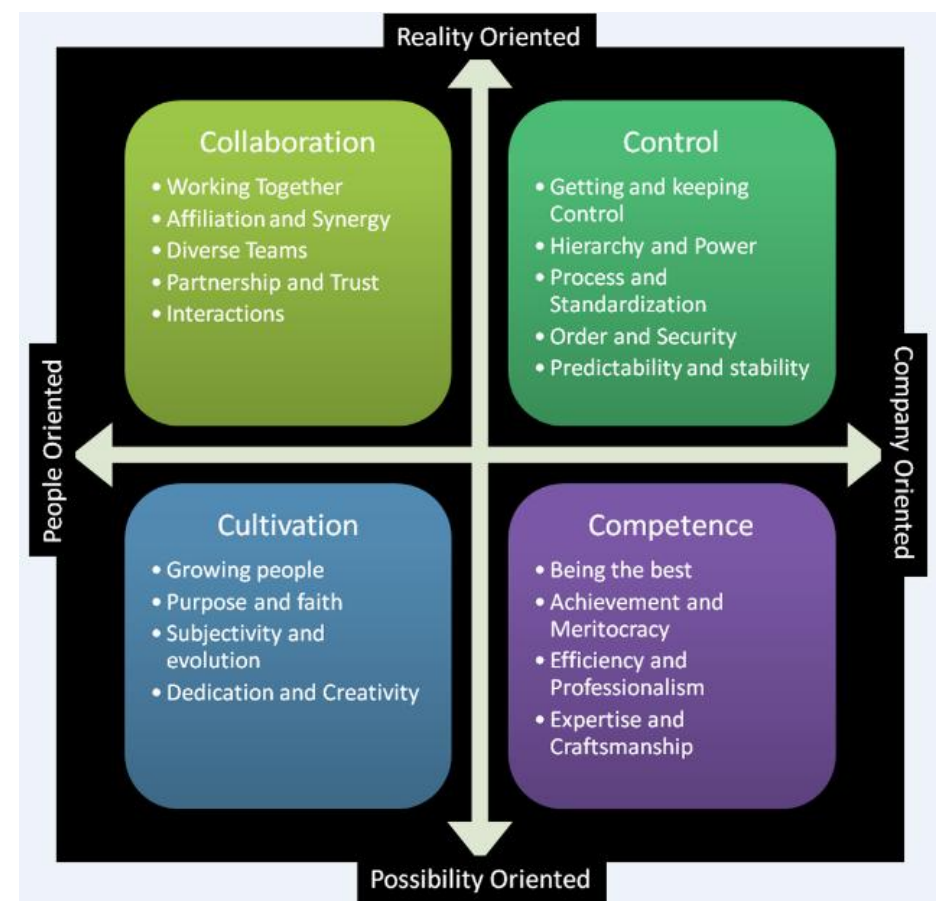

Figure 1. The Demonstration of the Culture Oriented Background

In this paper, we conduct research on the national traditional sports resources in the Lancang river valley under culture oriented background. National traditional sport is the people of all ethnic groups in the different historical development of our country, on its own spiritual wisdom created the brilliant national culture. It, like the other national culture, is the treasure of Chinese national culture and is the crystallization of the wisdom of the people. Traditional athletic swimming in the broadest sense of the entertainment culture is the traditional mode of competitive sports activities and entertainment game activities, it belongs to and is rooted in the national traditional sports culture is the core part of the national traditional sports culture. In the later sections, we will discuss the issues in detail.

\section{The Proposed Methodology}

The Culture Oriented Background. With Confucianism as the mainstream of Chinese culture in the development process of the thousands of the years, while also faced all kinds of cultures, including the challenge of Indian culture, a series of adjustment, but after their own stubbornly continue down, and did not change their main channel. Now the academia to culture the word has a broad sense and the narrow sense. The generalized culture refers to the human in the process of practice have created the sum total of material wealth and spiritual wealth [5-6]. 
Dominant value refers to people as a member of a group of people, for their behavior or words for communication, interpretation, logical, and proves the method as it reveals how people for them in the first cultural elements in level of meaning. Chinese culture believes in human goodness advocating nature and humanity. On the basic hypothesis of interpersonal relationship, to accept person born unequal status and relationship between, but pursuit of harmony of inequality, think the harmonious interpersonal relationship is an important source of happiness in life, is also the ultimate purpose of the relationship between behavior in order to achieve this goal, people need to group interests above personal interests on the one hand, on the other hand need act in accordance with the rites.

This is a fusion of ancient and modern, Chinese spirit of facing the world. It is associated with the modernity of the world, and is associated with the characteristics of ancient Chinese. While pay more attention to the diversity and particularity of national culture, and beyond this level and perspective to the universality of the human race has one and the convergence, we in the new rational guidance, reinterpret distorted the national fable, reasserting Chinese cultural image of the repressed. It really should be in the world in the era of the globalization on traditional Chinese culture to participate in the reconstruction of the call of the world thought.

The Characteristics of the National Sports. Under background of globalization, modernization of national traditional sports is from traditional sports to the dynamic development of modern social transformation process. This paper attempts to traditional sports into a multidimensional stereo space, all-round, multi-angle, multi-level discusses the general characteristic of national traditional sports modernization. The culture of a nation not only should be the same as the rest of the world culture and content, but also should be different from other special national form of national culture. The Chinese traditional sports not only have a long history, the rich accumulation, and there are many precious treasures have the important significance for human beings in the future. In today's modernization, globalization, national traditional sports only make more strong ethnic characteristics, culture is more abundant that can bloom in the world, for China and world sports and cultural resources and infinite vitality. Accordingly, the characteristics could be summarized as the follows.

- Athletics is the national traditional sports culture and the blend of modern sports culture. From the height of the world to look at themselves, actively participate in the cultural exchanges in the world, actively learn from the outstanding achievements in the modern sports and at the technique level using the modern sports science theory and the method to carry on the rational judgment and creation, refer to the organization system in the modern sports success in system level rapidly developing themselves [7]

- Folk accumulating national ancient relic is the source of national traditional sports activities. Folk once formed, will become standardize people's behavior, language and psychology of a kind of basic power, is also a popular habit and results of inheritance and the accumulation of culture to create a kind of important ways. Important way of this kind of life culture, national traditional sports was in large part in the national holiday of folk activities and produce, and within a certain specific area or region.

- Keeping fit is national traditional sports value. Influenced by the traditional culture of ethnic traditional sports in China, the pursuit of the unity of body and mind, cultivate one's morality raises a gender, combination of dynamic and static state, advocating the spirit of "harmony", its unique fitness value is the modern athletic sports can't replace. 
Due to the development of the national traditional sports culture with local and national character, cultural differences cannot simply through distribution or primary and redistribution simply achieve modernization. So at the time of the development of national traditional sports should respect the law, to protect the heterogeneity of sports culture, protection of national traditional sports culture and the national characteristics that pay attention to highlight the theme of national features, to keep the core content of the native. In addition, national traditional sports tourism can't because the pursuit of simple, extensive development and destructive exploitation, and feel free to mix the factor of modern society but at the same time in the development of pay attention to keep the primary original national characteristics and national culture because, when cultural environment to survival of once destroyed, the development of national traditional sports will appear alienation. For traditional Chinese national sport, it is rooted in the specific geographical environment and historical and cultural background, national character formed distinct characteristics.

The Lancang River Valley Features. The Lancang river basin is very broad, living here for many ethnic minorities. Here has a special geographic location, the absorption of the ethnic culture with the culture compatibility, etc. to become the cradle of Chinese culture. Here, the different ethnic groups have their own characteristics, has a competitive, entertaining folk traditional sports. These projects mainly originated from the countryside, easy to carry out the activity, the demand is low. Under the new rural construction to basic rural traditional minority national sports development provides a good condition. Traditional sports activities to create a better life for people also can have a healthy body. However, in some basic areas of the River basin, because in a mountainous area, the local economic development is limited by a lot of, some of the regional economy is relatively backward, and public sports installations and facilities also can't satisfy people's needs [8].

The comparative study found that the Lancang river basin and the Yunnan-Guizhou plateau found shoulders grinding stone, the type system of the east and south coastal areas of Guangdong, southern Guangxi and Indochina and found much closer to the Malay peninsula there are many similarities and even the same place. Traditional minority national sports to improve the villagers' ideas to enhance national cohesion play an important role. Sports culture needs into the mind of people to make people aware of sports activities, because people are becoming more and more attention to health, sports participation is indispensable. People in the process of participation in sports activities, can carry on the good communication with the others, we can also eliminate some troubles in life, so, many of the villagers like to participate in these sports. The villagers to enjoy life in the traditional culture and can also actively experience the charm of national sports.

The Traditional Sports Resources in Lancang River Valley. Based on the investigation to the domestic and foreign Lisu distribution can be found: the Lisu in different region, by accepting and integration of different cultures, to form the same in different group of diversified Lisu. Lisu this multicultural phenomenon, mainly affected by two factors: one is a natural choice, namely the Lisu of different geographical areas due to geography ontology cultural variation. Another is a natural choice, namely due to human factors scattered Lisu, strong in the integration of the regional culture after the formation of the cultural variation of ontology.

Lisu national traditional sports is not early now form a particular pattern of activity, only exists in different survival activities, not have a separate existence conditions and the space. With regional survival adapted to the drive, natural and not natural selection that made with a certain period of time corresponding to the regional 
culture of sports produce continuously, eventually formed the now we can see the Lisu ethnic traditional sports that could be summarized as follows.

- The nationality of sports culture. It can be seen from the material level and spiritual level, traditional sports, which fully reflect the characters is specific reflection of history, culture, consciousness, and production life, customs, ethics, religious ritual, festival activities, such as comprehensive reflection, show the characteristic of the nationality.

- Fun of sports culture. Adjust the production and living of monotonous, often is about together for two or more people skills, strength, show man's strong body, sensitive, they often choose some loved by traditional sports project such as penetrating crossbow, dozen gyro, wooden bridge, climb the pole to pick fruit, broken wrist, for game activities such as wrestling, rob in they mainly in the process of the participation is not to win, but to enjoy the game bring them happiness, in the process of looking for the joy in life [9].

- Education of sports culture. People are a brave and hardworking people, they created in the production environment and production life colorful traditional sports activities, these activities after continuous succession, loved by them, and their recognition of the traditional sports culture. Traditional minority national sports is a part of our country sports his education was gradually pay attention to and digging, its value and function of recognition.

\section{Conclusion}

In this paper, we conduct research on the national traditional sports resources in Lancang river valley under culture oriented background. Each national culture is to adapt to nation, and the characteristics of the formation and development of have the independent character and the social consciousness, in the generations of self-replicating history origin, constantly to undertake the external influence and variation, gradually formed and enrich the national culture. Five thousand year history of the Chinese nation has created many excellent traditional cultures as national traditional sports culture is one of a flower. Due to the formation of ancient times and a wide range of movement form rich variety, and rooted in the ancient traditional culture, so to master its connotation has brought the certain difficulty. With this basis, our research proposes the novel perspectives on national traditional sports resources in Lancang river valley with the integration of the literature review. In the future research, we will combine more survey to optimize the contemporary research.

\section{References}

[1] Tong-dan, Y. A. N., et al. "Investigation and Study on Graduates Employment Status of the Martial Arts and National Sports Traditional Sports in Sports College." Journal of Harbin Sport University 1 (2015): 014.

[2] Zhimin, Liu. "Research on the Protection and Utilization of Xinjiang Minority Traditional Sports Culture in Assisting Xinjiang Construction Opportunity." Journal of Tarim University 2 (2014): 011.

[3] Broglio, Steven P., et al. "National Athletic Trainers' Association position statement: management of sport concussion." Journal of athletic training 49.2 (2014): 245.

[4] Xiong, S. U. "This Paper Focuses on the Study of the Traditional National Sports in the Western Guangdong Areas [J]." Journal of Nanjing Institute of Physical Education (Social Science) 4 (2012): 006. 
[5] Anderson, Eric, and Edward M. Kian. "Examining media contestation of masculinity and head trauma in the National Football League." Men and Masculinities 15.2 (2012): 152-173.

[6] McMillan, Rachel, Michael McIsaac, and Ian Janssen. "Family Structure as a Correlate of Organized Sport Participation among Youth." PloS one 11.2 (2016): e0147403.

[7] CHAI, Zhi-ming, and Hua ZHANG. "Survey on Application of Sports Activities in Kindergartens of Urban Areas of Xinzhou
City." Sports Research and Education 2 (2012): 017.

[8] Guang-you, D. U. "Boosting and Spreading Chinese Traditional Sports Culture, Enhancing National Cultural Soft-power." Journal of Harbin Institute of Physical Education 1 (2014): 005.

[9] LIU, Jun-jie, and Ting CAO. "Research on the Meta-sports Science-The only way of Sports Science to mature." Journal of Hebei Institute of Physical Education 5 (2012): 002. 